\title{
Nanostructured thin film coatings with different strengthening effects
}

\author{
Yury Panfilov, ${ }^{1 *}$ \\ ${ }^{1}$ MSTU named after Bauman, Electronic Technology in Machinery Chair, 105005 Moscow 2-d Baumanskay St., 5, Russia
}

\begin{abstract}
A number of articles on strengthening thin film coatings were analyzed and a lot of unusual strengthening effects, such as super high hardness and plasticity simultaneously, ultra low friction coefficient, high wear-resistance, curve rigidity increasing of drills with small diameter, associated with process formation of nanostructured coatings by the different thin film deposition methods were detected. Vacuum coater with RF magnetron sputtering system and ion-beam source and arc evaporator for nanostructured thin film coating manufacture are represented. Diamond Like Carbon and $\mathrm{MoS}_{2}$ thin film coatings, $\mathrm{Ti}, \mathrm{Al}, \mathrm{Nb}, \mathrm{Cr}$, nitride, carbide, and carbo-nitride thin film materials are described as strengthening coatings.
\end{abstract}

Analysis of publications on functional and strengthening coatings published at special journals, e.g. "Strengthening technology and coatings", demonstrated that nanostructured thin film coatings are one of the main trend to increase of machine parts and of cutting and deformation tools durability, and decrease of mechanisms friction coefficient, as well. Choice of thin film deposition method and working has the grate influence to the strengthening effect and functional characteristics of the coatings.

The main methods of strengthening coatings manufacture are PVD (Physical Vapor Deposition): ionplasma sputtering and ion-beam deposition and arc evaporation with the reactive gas inlet into vacuum chamber. Vacuum coater with three types of sources - RF magnetron sputtering system, ion-beam source, arc evaporator - was elaborated for nanostructured thin film coating manufacture (Fig. 1).

The main of the technological and design versions are followings: substrate surface activation before thin film deposition, ion-beam assisted deposition, thin film deposition under angle between film-forming particle flow and substrate surface, multi-component and multilayer thin film deposition, as well.

Wear-resistant and antifriction strengthening coatings are manufactured by means of PVD methods. Thin film coatings structure and the main characteristics of the coatings are determined by thin film deposition process.

Gas pressure and substrate temperature and thin film rate of growth are the main parameters of thin film deposition process.

\section{Ion Beam Source}

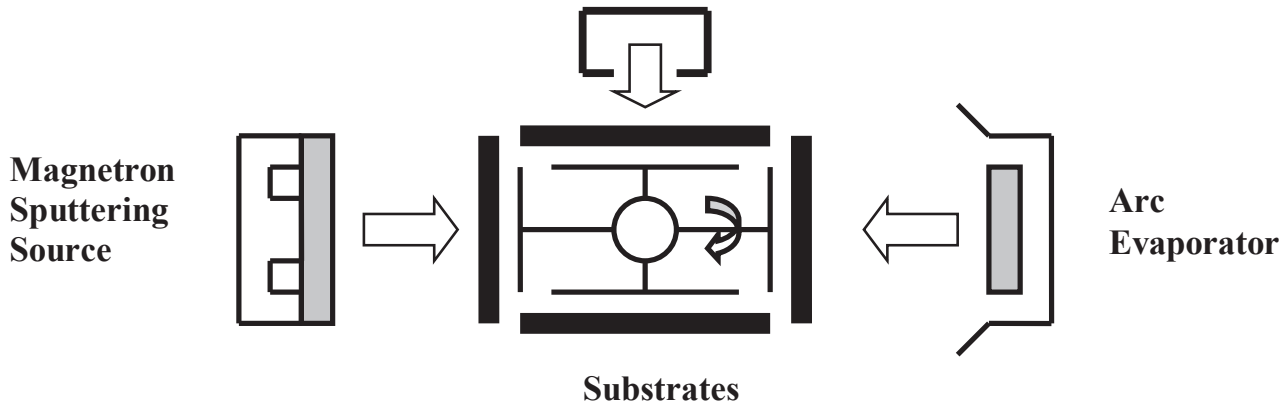

Fig. 1. Thin film deposition methods: magnetron sputtering, arc deposition, ion beam deposition and assistance.

An important application of thin film deposition in machine building is the strengthening of cutting and deformation tools by applying wear-resistant coatings. Using a composition with an optimum number of layers in the correct configuration ensures a high coating efficiency. The mono- or multilayer coatings are composed of nitride, carbide, and carbo-nitride compounds based on complex systems of high-meltingpoint metals (e.g., $\mathrm{Ti}, \mathrm{Nb}$, and $\mathrm{Cr}$ ).

\footnotetext{
*Corresponding author: panfilov@,bmstu.ru
} 
Thin film material and process variety (molecules flow and energy, substrate temperature) are the main advantages of PVD methods of a cutting and deformation tools wear resistance increasing. The compositions of titanium with silicon, boron and other materials provide an opportunity to nanostructure thin film wear-resistant coating manufacturing. Ion-plasma magnetron sputtering of multicomponent targets produced by means of the Selfdispersion High-temperature Synthesis (SHS) [1] is the method of this coating preparation.

High hardness (up to $70 \mathrm{GPa}$ ) and adhesion and low friction coefficient of TiBSiN, TiBCrN, TiAlCN and other coatings deposited by means of the SHS targets sputtering are thanks to thin film grains minimum dimensions of $1-4 \mathrm{~nm}$ [2].

Cutting tool wear resistance tests were provided by means of stainless steel samples drilling: $4 \mathrm{~mm}$ drills without wear-resistant coating and with thin film strengthening coatings, such as TiN and TiBSiN and $\mathrm{TiBCrN}$, were used in the test. The operating gas pressure of $1-2 \mathrm{~Pa}$, magnetron target voltage of $500 \mathrm{~V}$, ion current density of $800 \mathrm{~A} / \mathrm{m}^{2}$, reactive gas (nitrogen) concentration of $10-22 \%$ were the main thin film deposition parameters. Thickness of the coating was $400-700 \mathrm{~nm}$. The coatings were deposited via vacuum coater shown at Fig. 1.

Nanostructured strengthening coatings permit to increase of cutting tool durability and to increase of cutting process, as well. Cutting process increasing permits to decrease of pay for time of an expensive equipment. Dependence holes drilling time $t$ on the drilled holes number $\mathrm{n}$ when an equal loading to drill is shown at Fig. 2.

The TiBSiN thin film coating increased durability of the drills by about $3-4$ times in comparison with drills with TiN wear-resistant coating when stainless steel drilling. It was mainly due to decreasing of friction coefficient - a difference between chips (Fig. 3) was the result of the difference between the friction coefficients of the other wear-resistant coatings. The difference between chips was unexpectedly effect because chip of the drill with TiBCrN coating has small number of curves - the drill "went in steel as in butter".

Nanostructured thin film deposition by means of separate plasma of arc charging with carbon target provides of Diamond Like Carbon (DLC) coating manufacture with the next characteristics: minimum surface defects, high hardness (38 - $42 \mathrm{GPa})$ and adhesion, friction coefficient less than 0.2 at all friction way. DLC coating friction characteristics were tested at special experimental equipment.

DLC coating hardness and wear resistance were much bigger than indenter material (tempering ball) hardness and wear-resistance. So, there was wear of indenter, but not coating!

Unexpected strengthening effect was discovered after DLC coating deposition on drills with diameter of $50-$ $300 \mu \mathrm{m}$ for print circuit drilling - DLC thin film provides both of wear resistance increasing and curve rigidity increasing of drills [3]. Curve rigidity increasing of drills permits to increase preciseness of hall centers location after print circuit drilling.

Experimental research shown that curve rigidity of drills $0.105 \mathrm{~mm}$ diameter with DLC coating became up to $20 \%$ tougher in comparison with the drills without coating. Small diameter drill has very small rigidity so relational input strengthening coating to rigidity increasing may be very considerable (Fig. 4).

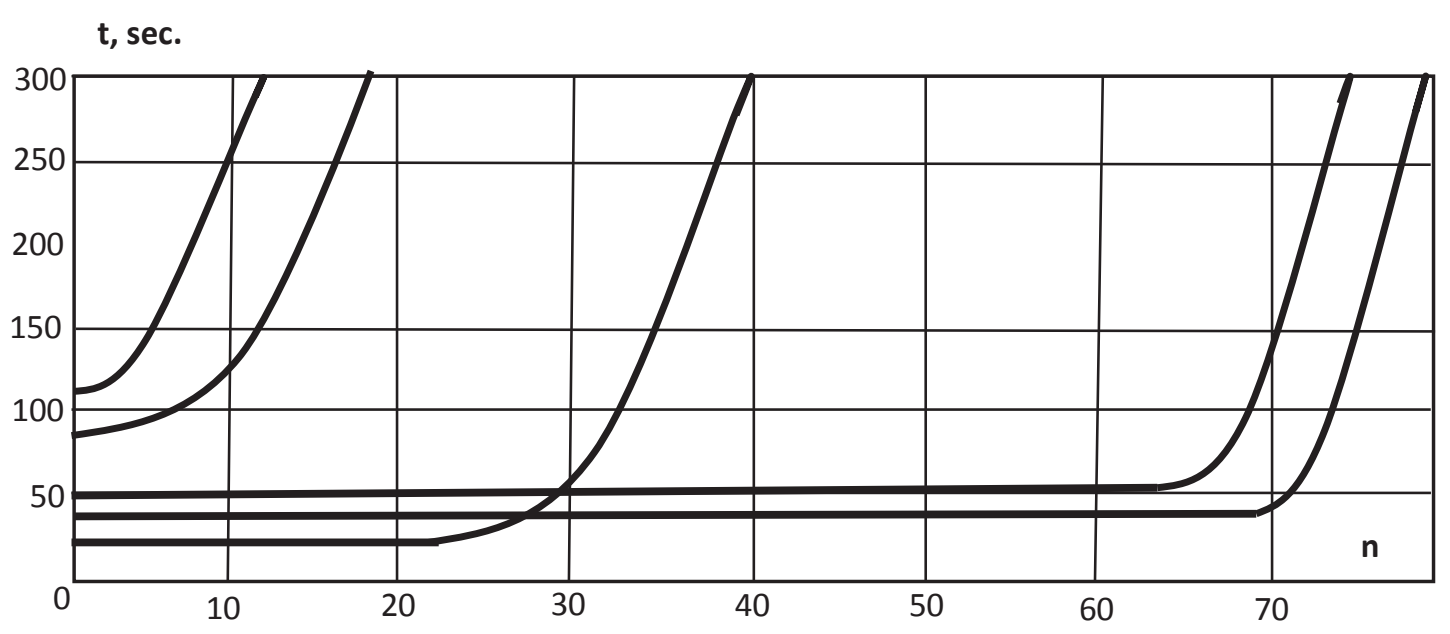

Fig. 2. Dependence holes drilling time $t$ on the drilled holes number $n$ when an equal loading to drill: 1 - without coating and with coatings: 2 - TiN, 3 - TiBCrN, $4-\mathrm{TiBN}+20 \% \mathrm{Si}, 5-\mathrm{TiBSiN}$. 


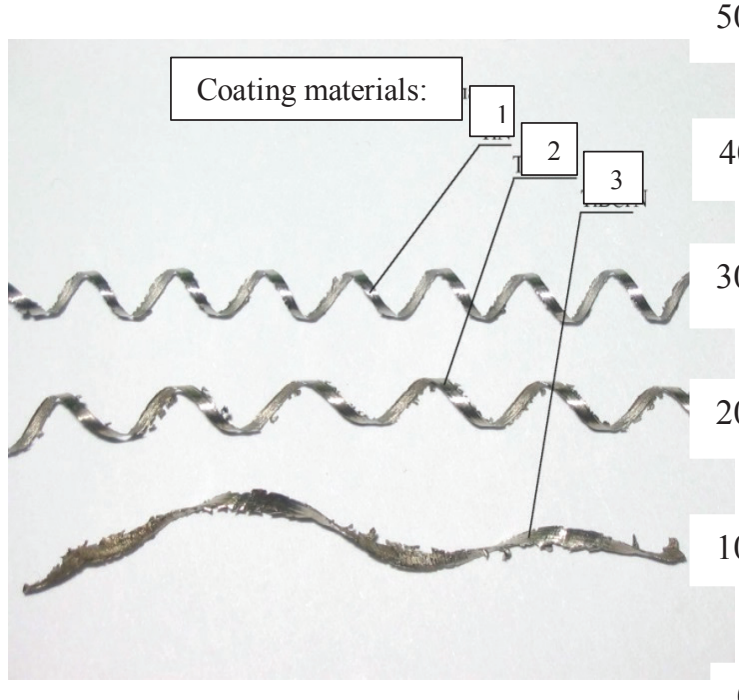

Fig. 3. Photo of drilling chips in dependence of coating materials: 1 - TiN, 2 - TiBSiN, 3 - TiBCrN.

Experimental test results of print curcuit drilling by 0.3 $\mathrm{mm}$ drills with DLC coating demonstrated that rootmean-quare error of drilled halls centers was decreased on $28.9 \%$ or $6.5 \mu \mathrm{m}$ in comparison with drilling by an initial drills (Fig. 5).

DLC strengthening coatings can be deposited by PVD and CVD (Chemical Vapor Deposition) methods. By means of vacuum coater (see Fig. 1), PVD methods only that is magnetron sputtering and arc evaporation of carbon targets were realized.

The best strengthening characteristics were obtained via arc evaporation with plasma flow separation because carbon ions only with high energy run into the substrate. So, the optimum correlation between deposited molecules mass and energy took place.

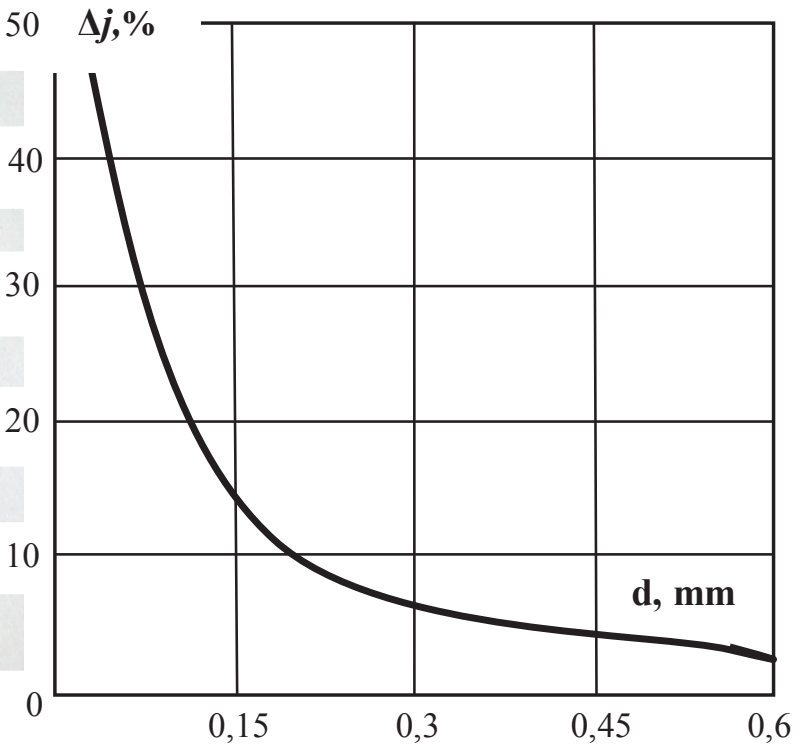

Fig. 4. Relational increment of curve rigidity $\Delta j$ of different diameter $d$ drills with DLC coating.

Ultra low friction effect was obtained by using antifriction thin film coating of $\mathrm{MoS}_{2} \mathrm{D}_{\mathrm{x}}$ compound ( $\mathrm{D}$ is dope element) at mormal conditions. Magnetron sputtering of two targets of $\mathrm{MoS}_{2}$ and Ga was used for manufacturing of this coating with sliding coefficient of $0.001-0.0001[4,5]$.

Model which explained of essence of antifriction action of $\mathrm{MoS}_{2} \mathrm{D}_{\mathrm{x}}$ coating with ultra low friction effect in normal condition at air was elaborated - dope element decreased of sliding friction between layers of $\mathrm{MoS}_{2}$. Dependance sliding coefficient of $\mathrm{MoS}_{2} \mathrm{D}_{\mathrm{x}}$ coating deposited by RF magnetron sputtering on testing time is shown at Fig. 6. The tests were carried out by disk-sphere scheme at air on normal conditions.

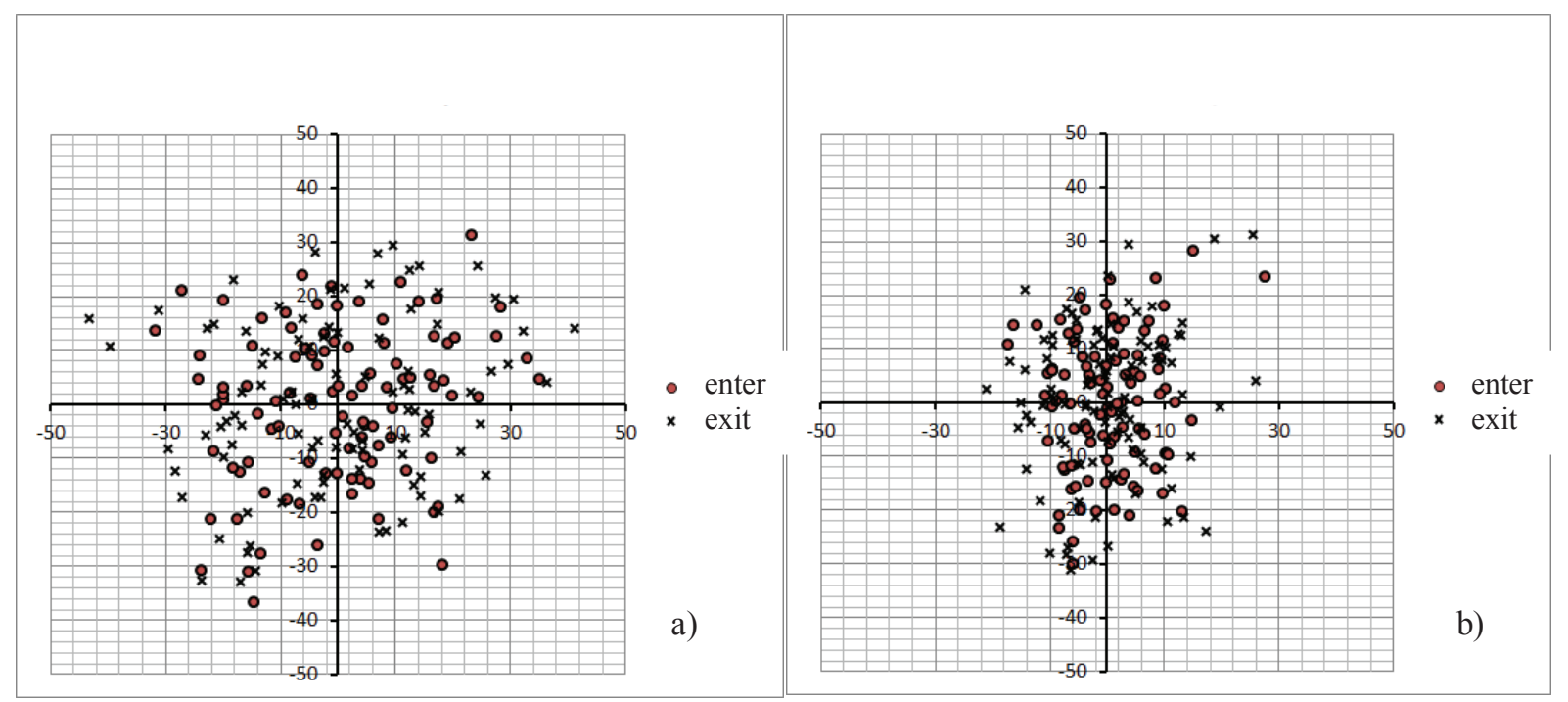

Fig. 5. Deviation of drilled halls centers $(\mu \mathrm{m})$ from nominal location for $0.3 \mathrm{~mm}$ drill diameter: a) drills without coating, b) drills with DLC coating. 


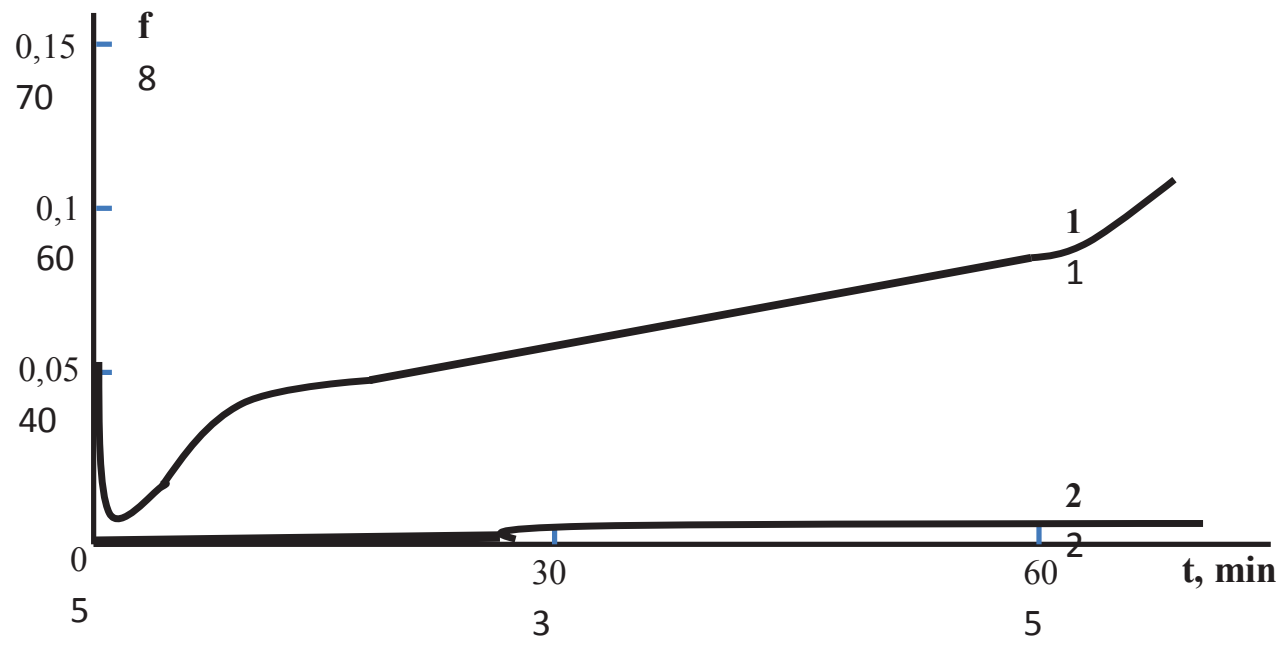

Fig. 6. Dependance of sliding coefficient $f$ on testing time $t$ of two coatings: $1-\mathrm{MoS}_{2}, 2-\mathrm{MoS}_{2} \mathrm{D}_{\mathrm{x}}$.

Thin film coatings with ultra low friction coefficient can be deposited by means of magnetron sputtering method at vacuum coater represented at Fig.1. The antifriction thin film coating of $\mathrm{MoS}_{2} \mathrm{D}_{\mathrm{x}}$ compound was deposited via two magnetron sources. Besides this, such coating can be manufactured by magnetron source with combined target which consists of two materials: $\mathrm{MoS}_{2}$ and dope element D.

\section{Conclusion}

Method and process of thin film deposition determine coating material energy and mass flow, thin film coating structure and functional chracteristics, as well. Besides this, unusial strengthening effects, such as super high hardness and plasticity simultaneously, ultra low friction coefficient, high wear-resistance, curve rigidity increasing of drills with small diameter, as well, are depended from coating material energy and mass transfer from source to substrate.

Vacuum technological equipment for strengthening thin film coatings deposition was developed. The coater includes vacuum dry pumps, ion-beam and ion-plasma sources of substrate surface cleaning and activation before thin film deposition, DC and RF magnetron sputtering systems, arc evaporator without drop phase and with plasma flow separation.

\section{References}

1. Y. Karabasov and others, New materials (MISIS, 2002)

2. E. Levashov, D. Shtansky, Y. Panfilov, Multicomponent nanostructure thin film wear-resistant coatings, 7th International Conference on Nanostructured Materials 35, (2004)

3. Y. Litvak, Y. Panfilov, Strengthening coatings application for increasing of micro-size drilling precision of print circuit, Strengthening technology and coatings 1, 5 (2016)

4. M. Nozhenkov, About weak interactions of particles in solid state materials, Nanoengineering 3, 7 (2012)

5. M. Nozhenkov, Cristal structure and properties of the coatings made by vacuum ion-plasma methods, Strengthening technology and coatings 9, 5 (2012) 